\title{
Choice of Practical Subjects: Is It Still a Gendered Phenomenon? A Case of Selected Co-educational Secondary Schools in Bulawayo Metropolitan Province, Zimbabwe
}

\author{
Dr. G. V. Nani \\ National University of Science and Technology, \\ P O Box AC939, Ascot, Bulawayo, Zimbabwe \\ Graduate School of Business, Faculty of Commerce \\ Dr. L. Sibanda \\ National University of Science and Technology, \\ P O Box AC939, Ascot, Bulawayo, Zimbabwe \\ Department of Science, Mathematics and Technology Education, \\ Faculty of Science and Technology Education
}

Doi: 10.2478/jesr-2019-0017

\begin{abstract}
The purpose of this study was to find out whether the selection of practical subjects in schools was still a gendered phenomenon. The motivators were findings of an investigation on business imitations in the Bulawayo Metropolitan Province, which revealed that men and women still participated in gender based entrepreneurial activities. A qualitative approach, which utilised the case study design was adopted for this study. Self-administered open-ended questionnaires were used as data collection instruments. The sample comprised 5 Heads of Departments, 15 practical subject educators and 75 students from 2 purposively selected co-educational schools in the Bulawayo Metropolitan Province. Data were analysed according to research questions. Findings showed that there were attempts to break the gender barriers as some girls were now studying subjects that were previously male dominated and some boys had enrolled for subjects that were in the past the preserve of girls. The study concluded that there was a gradual paradigm shift in the mind-sets of school authorities, learners and some parents. Recommendations were that school authorities should continue to intensify campaigns on deconstructing the learners' gender stereo typed mind-sets and engage various stakeholders in the change process to enable learners to comfortably fit in a globally competitive environment.
\end{abstract}

Keywords: co-educational secondary schools, choice, gender, gendered phenomenon, practical subjects

\section{Introduction}

The selection of practical subjects based on masculinity and femininity has been a concern, with some people blaming the practice on the gender socialisation embedded in the patriarchal value system which manifests itself in the educational curriculum. Bigler, Hayes and Hamilton (2013) define gender socialisation as a process through which children learn about the social expectations, attitudes and behaviours typically associated with boys and girls. Schools are major contexts for gender socialisation because that is where learners spend large amounts of time. Educators and peers shape learners' gender attitudes and in turn gender differences in cognition and behaviour. Mutekwe and Modiba (2012) assert that consequently, the occupations by men and women tend to be aligned towards cultural expectations and behaviours of that particular society. 
However, there have been attempts by governments in various countries to demystify this myth of 'boys' only and 'girls' only subjects (International Labour Organisation (ILO), 2004).

Literature suggests that girls everywhere have been experiencing lower levels of parental investments when they are younger, be it via family structure, parents' time or educational investments (Bharadwaj \& Ketkisheth, 2010). Some positive changes have been noted though, in both developed and developing countries. Developed countries such as those in the European Union have of late witnessed significant improvements as female students are enrolling for subjects that were predominantly the male domain (ILO, 2004). In developing countries too, where all along parents preferred educating the boy more than the girl child, educational opportunities have been availed to both, irrespective of gender (Khumalo, 2006; Makombe, 2006).

This study sought to find out if learners in the Bulawayo Metropolitan Province were still selecting practical subjects on the basis of gender.

\section{Background}

Even in Zimbabwe, parents preferred to educate boys more than girls. However, the Government of Zimbabwe has been concerned about gender imbalances since 1980. Through its active participation in various national, regional and international fora and conferences on gender equality and equity issues, Zimbabwe has made several attempts to close this gender gap (Mapolisa, Tshabalala \& Ncube, 2015). In addition, Zimbabwe is a signatory to most of the fundamental conventions designed to achieve gender justice across sectors which include the: Convention on the Elimination of all forms of Discrimination Against Women (CEDAW) (1991); the Beijing Declaration on the Platform for Action (1995); the Convention Civil and Political Rights (CCPR); the Equal Remuneration Convention; Convention on the Prohibition of Discriminations in Occupations and the 2004 Solemn Declaration on Gender and Equality in Africa, among the many conventions (The National Gender Policy, 2013 -2017).

At national level, Zimbabwe has amended and has passed 17 pieces of legislation to advance the gender equality and equity objective. Some of these include the: Matrimonial Causes Act (1987); Maintenance Act (1999); Education Act (1987) and the Domestic Violence Act (2007). The Constitution of Zimbabwe adopted in 2013 is widely acknowledged for its firm commitment to gender equality, and the right to education for all, has been a long standing commitment for Zimbabwe.

Amongst all the Acts that Zimbabwe has passed, of significance to this study is the Zimbabwe Education Act (1987), Chapter 25/04, Part II, Section 4 which gave every child, irrespective of gender, the fundamental right to education (Zimbabwe Education Act (1987), Chapter 25/04, Part II, Section 4). However, gender stereotyping of subjects in secondary school level, and courses at tertiary level also presented challenges (National Gender Policy, 2013-2017). Mapolisa et al., (2015) agreed with the afore-said that it was generally believed that there was a gender imbalance in practical subjects in most schools. Mutekwe and Modiba (2012) asserted that boys and girls thus developed different and polarised roles that limited the horizons of girls by locking them into a gender stratified occupational world. The same authors further postulated that the unequal distribution of boys and girls in certain subjects studied at school suggested some failure by schools and teachers to institute adequate measures to ensure learning equity.

This study, therefore sought to find out whether the efforts by government had translated to reality through investigating if the selection of practical subjects was still based on gender, taking into account the findings of a study on business imitations which showed that entrepreneurial activities were largely based on gender. The aim was that if the results were in the affirmative, attempts would be made to alert policy makers to intensify their efforts of discouraging this practice as the society we now live in, is striving for a non-gendered approach to life in every respect.

\section{Statement of the Problem}

Practical subjects are meant to equip learners with knowledge and skills to create their own selfemployment. It is generally believed that there is a link between the practical subjects studied and 
the type of business one will embark on. However, the practical subjects studied by girls excluded them from the mainstream economy (Wirth, 2001). According to Mapolisa et al., (2015), boys were encouraged to study Metalwork, Woodwork, Building and Agriculture which were regarded as masculine subjects while girls mainly pursued domestic science, typing, shorthand, secretarial studies and arts subjects. Yet a study by the same authors in Umguza District of Zimbabwe revealed that girls could perform the same as boys if not even better, in the traditionally male dominated practical subjects. After independence, the Government of Zimbabwe through various acts and policies attempted to de-construct this type of mentality. In spite of government efforts, research still showed that entrepreneurs were still aligned towards gender based businesses.

This gender disparity surfaced in a study by Nani and Radipere (2016) on business imitations in the Bulawayo Metropolitan Province, Zimbabwe, where more women imitated businesses were in the previously female dominated sectors while there were more men in what used to be male dominant sectors. This is despite the fact that some of the participants had been exposed to the two Pathway Education curriculum which embraced the learning of core and practical subjects irrespective of gender. This prompted the current researchers to investigate whether the career choices that the participants had made depicted the situation still obtaining in the schools, that is choosing subjects according to gender. One would have expected that after concerted efforts by the government to close the gender gap, there would now be changing patterns even in the types of businesses pursued by men and women. This study contributes by being the first of its kind in the Bulawayo Metropolitan Province to investigate if the selection of practical subjects is still a gendered issue. Findings from such a study will provide policy makers with insights to make informed decisions in curriculum reviews.

\section{Primary Objective}

To find out if the choice of practical subjects in secondary schools is still a gendered phenomenon.

\subsection{Secondary Objectives}

1. To find out if schools still offer subjects on gender lines.

2. To find out factors that influence learners' choices of practical subjects in the selected schools.

3. To determine the challenges faced in offering subjects across gender lines.

\section{Literature Review}

The study used the gender socialisation process as the theoretical lens with which to examine whether the selection of practical subjects in schools was still a gendered phenomenon (Bigler, Hayes \& Hamilton, 2013). According to Bharadwaj and Ketkisheth (2010), gender differences found in adulthood are in part a product of an individual's environment during childhood. Mutekwe and Modiba (2012) contend that Zimbabwean girls were educated for domesticity while boys were prepared for employment and the role of family head and breadwinner. However, a study by Nani (2013) revealed that access to educational opportunities by women had brought about social transformation and change in the way that women viewed themselves. Women were able to participate in activities that they did not before, such as engaging in businesses which financially empowered them instead of being wholly dependent on men.

The choice of practical subjects by learners can be determined at two levels; the home and school. In the home, it is the family, mainly parents that influence the subjects their children choose while at school level, it is the infrastructure, curriculum, teachers, peers and general culture of the school (Mutekwe \& Modiba, 2013). Although the choice of practical subjects by learners can be determined in part by influence from home; this study focused mainly on influence by the school for these reasons. According to Bigler et al., (2013), schools affect gender differences via two primary sources; the educators and peers. Schools are major contexts for gender socialisation because learners spend large amounts of time engaged with peers. Fousiya and Musthafa (2016) concur 
that the school not only defines what to teach but also defines and regulates both what a girl or boy is and how learning and teaching are to be conditioned for him or her. Bigler et al., (2013), further assert that the experiences afforded to girls and boys within schools affect gender differentiation both directly, by providing differential skill practice and reinforcement and indirectly, by providing input that leads learners to actively socialise themselves along gender differentiated pathways. Educators present curricular materials that contain gender stereotypic behaviour and peers exhibit gender stereotypic attitudes and behaviour which learners internalise and use to guide their own preferences and behaviours. Peers segregate themselves according to gender and it is this gender segregation that predicts learners' future conformity to gender stereotypes (Bigler et al., 2013). Fousiya and Musthafa, (2016) agree that by so doing, some educators unknowingly reinforce gender discrimination already prevailing in society.

Based on the aforementioned, a similar situation prevailed in Zimbabwe where the school reinforced values, norms and behaviour based on gender. Mutekwe and Modiba (2012); Moyo (2009) and Nyathi (as cited in Nani, 2012) contend that before Zimbabwe's independence in 1980, there were subjects that were traditionally meant for 'boys' only and 'girls' only. This practice was based on the belief that girls were incapable of doing more challenging subjects such as science and mathematics and only boys could. As a result, boys' education and training was heavily biased towards science and mathematics. According to Central Statistics Office (CSO) (2002), even in technical colleges, female students mainly specialised in subjects such as hair dressing, secretarial studies and hotel keeping whereas male students studied engineering, a crucial skill to the economy.

However, as previously alluded to, the Government of Zimbabwe has made attempts to redress marginalisation in terms of gender. One of the measures at educational level was the passing of the Education Act 5 of 1987 (later amended) which gave every child the right to education irrespective of gender. Another measure to ensure gender equality in the educational system was the adoption of the Affirmative Action in the entire national education and tertiary training systems following the Fourth World Conference on Women in Beijing in 1995 (Stewart et al., 2000). Despite its nobility, Affirmative Action has received criticisms for portraying a girl child as someone who has to be assisted to make any academic achievements. These critiques fail to appreciate that the girl child was marginalised for a long time and the government was trying to bridge the gap.

The Nziramasanga Commission (1999) meant to ensure the adoption of practical subjects in the school curriculum was yet another indication by the government to make educational opportunities open to everyone through the integration of core and practical subjects. The recommendations by the Nziramasanga Commission were that students should study a minimum of two practical subjects in addition to the core subjects. The core subjects are English Language, Mathematics, Science, isiNdebele/Shona, Geography and History. The practical subjects include Woodwork, Metalwork, Fashion and Fabrics, Food and Nutrition, Agriculture, Computer Science and Technical Graphics (The Nziramasanga Commission, 1999). According to the Policy Circular Number P77 of 2006, the two pathways are:

* The General/ Academic Education pathway core subjects, and

* The Skills pathway i.e. the Business/ Commercial/ Technology/ Technical - Vocational Education pathway to cater for the interest, aptitude and demands of the students' career choices.

* The Policy requires that all Zimbabwean Secondary Schools comply (Mahere, 2006).

The policy did not specify the practical and vocational subjects according to gender but the liberty to choose which subjects to study would lie with the individuals. By not being gender specific on the choice of practical and vocational subjects, the Government of Zimbabwe was trying to deconstruct the gender role stereotypes.

\section{Methodology}

The study was a qualitative research that utilised the case study design. The qualitative methodology was preferred for this study in order to find out the participants' perceptions, beliefs, 
attitudes and feelings (Cooper and Schindler, 2008) concerning the selection of practical subjects. Before the empirical study was conducted, permission was sought from the Ministry of Primary and Secondary Education and also from the Heads of targeted schools. Self-administered open-ended questionnaires were used to collect data from a sample of 5 Heads of Departments (HODs), 15 practical subject educators and 75 learners from 2 purposively selected co-educational schools. Open-ended questionnaires were meant to ensure that participants dealt with the same questions and issues for corroboration purposes. The researchers purposively selected co-educational schools because both sexes were found and the selected schools offered all types of recommended practical subjects. Reponses to the open ended questions were post coded and the analyses were based on the themes that emerged from the research questions. Findings were narratively discussed. All the questionnaires administered to HODs were retrieved. Out of the 15 questionnaires distributed to practical subject educators, 13 responded while from the 75 questionnaires distributed to learners, 66 learners responded. All the retrieved questionnaires were usable for data analysis.

\section{Analysis and Discussion of Results}

The study sought to establish if the choice of practical subjects in secondary schools was still a gendered phenomenon; to establish the factors that influenced learners' choices of practical subjects in selected schools and the challenges faced in offering subjects across gender lines. The discussion that follows is presented according to emerging themes derived from the research questions.

\subsection{Practical subjects offered in schools}

Pertaining to practical subjects which were offered by the schools under study, the results from the Heads of Departments, educators of practical subjects and learners from the two selected coeducational schools; the five commonly offered practical subjects are Technical Graphics, Metal Work, Wood Work, Food and Nutrition and Fashion and Fabrics. However, one of the two schools indicated Agriculture, Home Management, Music and Computers as the additional practical subjects.

\subsubsection{Practical subjects predominantly done by boys or girls}

In response to whether the schools under study still have practical subjects that are predominantly done by either boys or girls, the HODs, educators and learners in this study indicated that although Metal Work and Wood Work had a higher intake of boys and Food and Nutrition had more girls, there were noticeable changes. Some boys were enrolled in Food and Nutrition which was previously dominated by girls and some girls were now studying Technical Graphics, a boys' subject. Besides, the curriculum did not specify uptake of practical subjects according to gender. However, the participants were quick to point out that the change process was slow and it was likely to take some time as de-constructing values and attitudes that were ingrained in the learners since childhood were unlikely to be eradicated in the short term. The following responses from HODs, educators and learners confirmed the positive changes.

"Students now choose the subjects they want to study."

"No. Food and Nutrition has made gainful inroads because we see boys taking the subject seriously and writing the examination at Ordinary Level, but with Fashion and Fabrics, it has been a challenge."

"Although boys still dominate in Metal Work and Woodwork, there are some girls who have enrolled for the subjects. Some girls are also studying Technical Graphs which was mainly selected by boys."

"Boys and girls are now free to do subjects that they have a passion for though sometimes they are restricted by the timetable."

"A good number of girls have seen the light and are taking up subjects that they did not before like Wood Work and Metal Work but the challenge is mainly parental influence as they feel that these 
subjects are not meant for girls."

"A reasonable number of boys has come to appreciate the importance of practical subjects like Food and Nutrition, previously a girl's subject, especially for those who want to venture into catering."

The interest by boys in Food and Nutrition and girls in Wood Work and Metal Work is a direct contrast of what used to be portrayed by the educational system. According to CSO (2002), in technical colleges, female students mainly specialised in subjects such as hair dressing, secretarial studies and hotel keeping whereas male students studied engineering, a crucial skill to the economy. However, there is a shift of interest by boys who have now registered for Food and Nutrition, and girls for Wood Work and Metal Work the subjects which were viewed predominantly female and male specialties, respectively. These findings are a pointer to a change in values and perceptions of boys and girls.

\subsubsection{Reasons on whether it is good to have 'boys' only and 'girls' only subjects}

Some of the participants felt that it was not good for subjects to be gendered as girls can have talents in the subjects that have always been considered to be suitable for boys only. The other reason given was the need for learners to be multi-skilled. The following verbatim statements attest to the afore-said.

"Gender should not be a barrier; otherwise our career opportunities can be limited."

"As learners we need to interact so as to share ideas for the development of our country."

"Some of our talents were hidden because of the gender bias. Now is the time to discover them."

\subsubsection{Ratio of boys to girls in practical subjects offered}

The HODs and educators unanimously agreed that there were more girls than boys in Fashion and Fabrics and more boys than girls in Metal Work and Wood Work. The situation was different in Technical Graphics. If the whole class was doing the subject, there would be more girls than boys because generally there are more girls than boys in schools. These results confirmed the observations by Mapolisa et al., (2015) that there was a gender imbalance in practical subjects in most schools. Although the ratios might not be equal, the good thing was that some learners were now showing interest in subjects across gender lines. The following response was obtained on the ratios of boys to girls in practical subjects.

"Numbers for each subject vary depending on the enrolment for each class but generally, we have more girls in what were predominantly girls' subjects and more boys in what used to be the boys' subjects. However, we are witnessing a change in attitudes as students cut across gender."

\subsection{Factors that influenced the choice of practical subjects that the learners were doing}

In response to the question directed to learner participants, they revealed that there were numerous factors that influenced the learners' choices of practical subjects which encompassed interest in the subject, aptitude, career paths, parents, peers and the school's selection criteria as shown in the responses that follow:

"It was my own choice. I have a passion for the subjects, generally. I love working with metals."

"I chose the practical subjects I am doing because there are many career opportunities for these subjects. I want to open up my own restaurant."

"I was influenced by market demands."

"No one influenced me to choose Food and Nutrition because I am really good at this subject. I always score high marks."

"My sister told me to do Technical Graphics and Fashion and Fabrics."

"My brother is a chef, so I got advice from him and I also wanted to cook like my brother."

"Yes, because my mother learnt Food and Nutrition at school, so she thought that if I do it as well I will pass." 
Although the majority of learners indicated that they had chosen the subjects out of their own volition, it is a fact that some learners had external influence in the selection of their practical subjects. For example some learners made the following contribution:

"It was influence from parents, educators, peers and siblings."

These findings are in tandem with views by Bigler, Hayes and Hamilton (2013) that educators and peers shape learners' gender attitudes and in turn gender differences in cognition and behaviour. Bharadwaj and Ketkisheth (2010) concur that gender differences found in adulthood are in part a product of an individual's environment during childhood.

While it was true that the educational system had limited the horizons of girls by locking them in a gender stratified occupational world (Mutekwe and Modiba, 2012), according to the findings there were noticeable changes. This is confirmed by the learners in their responses below:

"There is gender equality now."

"You find a mixture of boys and girls in Food and Nutrition and Technical Graphics."

"There are female engineers these days. Why should we have subjects meant for boys only?"

"We have to remove male dominance. This is the 21st century. We cannot continue to live in the past."

The afore-said now contradict what Mutekwe and Modiba (2012) had found out in their study concerning Zimbabwean girls being educated for domesticity while boys were prepared for employment. These results consolidate the views by Nani (2013) that access to educational opportunities by women and girls had brought about social transformation and change in the way women and girls viewed themselves. While in the past girls would view themselves as only good enough for domesticity, the situation was slowly changing due to exposure to education.

The implication is that there is a change of attitudes and perceptions that is depicted in these results.Furthermore, these findings are a pointer to a change in attitude where before Zimbabwe's independence in 1980, there were subjects that were traditionally meant for 'boys' only and 'girls' only (Mutekwe \& Modiba, 2012; Moyo, 2009; Nyathi as cited in Nani, 2012).

\subsubsection{How peers perceived the practical subjects done by learner participants}

Learners indicated mixed perceptions with some saying:

Responses from boys

"Some of my peers look down upon us because they say cooking is for girls but we do not mind."

"I have all the support from my friends."

"When girls outperform us, we get embarrassed as they laugh at us."

"Some boys are shy to do Food and Nutrition as their practical subject because it negatively impacts on their self- esteem."

\section{Responses from girls}

"Some feel pity for me because they think I am experiencing hardships."

"Boys used to underestimate us thinking that Wood Work and Metal Work were meant for boys only and we would not be capable."

"When I joined, boys thought I would not make it but now they respect me because I am at par, if not better than them."

"Girls are happy for me because they say I am their representative."

\subsubsection{How the learner participants have handled the challenges from peers}

"Some of our peers laugh at us and say we are doing girls' stuff and I ignore them."

"Some boys discourage me and say I will not be able to get employment in Food and Nutrition but I do not listen to them."

"Boys in Wood Work always make fun of me. They say they have never seen a woman carpenter 
but I am not discouraged at all. I know what I want in life."

Such comments are expected in a co-educational set up and from learners who have been socialised that there are some subjects for boys and others for girls. However, with time and as numbers increase, such comments are bound to disappear.

7.2.3 How the practical subjects that learner participants are doing help them in the career they want to pursue

The majority of learners who had responded that they were now studying practical subjects across gender lines indicated that the practical subjects that they were studying would enhance their career opportunities. Some girls said that they wanted to be fitters and turners, diesel plant fitters, carpentry educators and designers.

"Technical Graphics and Metalwork will contribute towards accomplishing my engineering dream.

They teach me to have entrepreneurial skills that will help me in future."

\subsection{How successful the schools were in getting boys to embrace subjects that were previously} done by girls

In response to this question, the Heads of Departments and learners indicated that they were seeing some gradual changes as some boys were now doing practical subjects that were previously studied by girls such as Food and Nutrition. Similarly, some girls were enrolling for subjects that were previously dominated by boys, for example, Technical Graphics, Wood Work and Metal Work, though there were some students from either gender, who were still choosing subjects based on gender.

7.4 How successful the schools were in getting girls to enrol for subjects that were previously done by boys

Both HODs and educators attested to the fact that although some girls were now learning subjects previously meant for boys and the girls alike, the uptake of these subjects was rather slow as some learners were still inhibited by gender biased values and perceptions regarding 'boys' only and 'girls' only subjects. The following verbatim statements are testimony to that.

\footnotetext{
"The process has been slow but when the boys get into it, they enjoy and appreciate the benefits of these subjects."

"To begin with, we faced resistance from parents and learners but now some learners are willing to do the subjects that were previously not in their domain. We now have to continue engaging parents to appreciate the need for their children to be multi skilled."

"A reasonable degree of success has been achieved. A sizeable number of boys have begun to embrace the learning of especially Food and Nutrition but we still have to deal with discouragements by their colleagues and some parents."

"Boys have shown a keen interest in especially Food and Nutrition and girls, Technical Graphics. We still have a long way to go with Metal Work and Wood Work. The community tends to discourage learners."

"Some boys are shy and some girls lack confidence to take up the subjects they want to pursue. However, with more career guidance, we expect the bias to be eradicated."
}

It is evident from the participants' responses that in the schools under study, the distribution of learners in practical subjects is slowly moving towards de-mystifying the gender myth.

\section{Conclusions}

The study sought to establish if the choice of practical subjects in selected co-educational secondary schools was still a gendered phenomenon; to establish the factors that influenced 
learners' choices of practical subjects in selected schools and the challenges faced in offering subjects across gender lines. Based on the results in this study, while there were some learners who still chose subjects according to gender, there were other learners who did not consider gender to be a barrier anymore. Some girls were now doing Technical Graphics and Metal Work while some boys were now into Food and Nutrition. Although the change seemed to be gradual, what was worth recognising was that culture was undergoing change. The socialisation process that learners went through was based on masculinity and femininity but learners were now breaking those barriers. The implication is that the effort by the government to de-construct the gender mentality and gender stereo typing is slowly paying dividends. The contribution that has been made by this study to the body of knowledge is that the patriarchal glass is gradually being shattered in schools. Socialisation is from birth; therefore the change might not be radical and because it is a process, it is bound to take some time. The study was a success because it unveiled that there were changes in the perceptions and attitudes of the school authorities, students and parents in line with societal changes and market demands.

\section{Recommendations}

Results in this study clearly showed that the selection of practical subjects on gender basis was undergoing some changes with some learners disregarding the masculine and feminine barriers that used to exist in the selection of practical subjects. However, there were some learners who still have the gender biased mind-sets. Based on these findings, the following recommendations were made: the need to intensify campaigns on de-constructing the learners' gender stereo-typed mindsets, conduct school audits to check on the uptake of practical subjects across gender and to continue to engage various stakeholders on the benefits of having learners who can fit in any situation irrespective of gender.

\subsection{Intensify campaigns on change of mind sets}

Schools and educators have been mandated to instil in learners, attitudes and values that will enable them to contribute positively towards the social, economic and technological development of the economy. It is in this regard that schools and educators as agents of change should perform these responsibilities in the best way possible. Educators are the ones who have been given the mandate to positively transform the minds of the learners towards positive development which goes beyond gender. Boys and girls alike should be assured of the potential they possess in various fields and should use the talents that they are endowed with to exploit the opportunities that they have been given.

\subsection{Conduct audits on the selection of practical subjects}

There is a need by policy makers and curriculum developers to conduct audits to check not only that schools have implemented the learning of the recommended practical subjects under the Skills Pathway Curriculum but also the uptake of practical subjects specifically on gender lines.

\subsection{Engagement of various stakeholders}

There is need to engage various stakeholders namely, education policy makers, schools administrators, schools development committees (comprising parents) and representatives from industry to enlighten learners on the factors that they should consider when making choices of practical subjects. Perhaps when captains of industry assure learners that the world of business no longer considers gender to be a barrier, learners might be enthused and that can boost the uptake of subjects across gender. 


\subsection{Areas for further study}

This particular study has shown that selection of practical subjects is slowly cutting across gender lines. Another study could be conducted to find out the role played by parents in the drive towards gender mind-set deconstruction in the selection of practical subjects.

\section{References}

Bharadwaj, P. \& Ketkisheth, G. B. D. (2010). Gender Discrimination in the family. San Diego: University of Calfornia. Retrieved from http://econweb.ucsd.edu/-gdah/papers/genderdiscrimination-in-family.pdf

Bigler, R., Hayes, A. R. \& Hamilton, V. (2013). The Role of Schools in the Early Socialisation of Gender Differences.Encyclopaedia on Early Childhood Development.Retrieved from http://www.childencyclopaedia.com/gender-early-socialisation/according-expert

Central Statistics Office (2002). Women and men in Zimbabwe. Harare: Government Printers

Cooper, D. R. \& Schindler, P. S. (2008). Business Research Methods. Singapore. McGraw-Hill. International Edition.

Fousiya, P. \& Musthafa, M. A. (2016). Gender Bias in School Curriculum Curbs Girls' Career Aspirations. IOSR Journal of Humanities and Social Science, 21 (3), 19-22.

International Labour Organization. (2004). Latest Update. Geneva. International Labour Office.

Khumalo, V. (2006).Women Entrepreneurs in Small, Medium and Micro Enterprises. A case study in Swaziland.Unpublished master's dissertation, University of the Free State, Bloemfontein, South Africa

Mahere, S. M. (2006). Policy Guidelines on the Implementation of the Two Pathway Education Structure in Zimbabwe. Policy Circular Number P77 of 2006. Harare:Ministry of Education Sport and Culture.

Makombe, I. A. (2006). Women Entrepreneurship Development and Micro-Enterprises in Tanzania. The Case of Sido/Unido Supported Women Micro-entrepreneurs in the Food Processing Sector.

Mapolisa, T., Tshabalala, T. \& Ncube, A. C.(2015). An Assessment of the Choice of Practical Subjects by Secondary School Pupils in Umguza District Secondary Schools. British Journal of Education, Society and Behavioural Science, 7(3), 176-183. Retrieved from www.sciencedomain.org

Mutekwe, E.\& Modiba, M.(2012). Girls Career Choices as a product of a gendered school. South African Journal of Education, 32 (3), 279-292

Nani, G. V. (2013).Urban Zimbabwean Women Entrepreneurs. Challenges and Opportunities. Bulawayo: Amagugu Publishers.

Nani, G. V. \& Radipere, N. S. (2016). An investigation on business imitations in the Bulawayo Metropolitan Province, Zimbabwe. (Unpublished) University of South Africa

National Gender Policy (2013-2017). The Republic of Zimbabwe. Ministry of Women's Affairs, Gender and Community Development. Harare: Government Publishers.

Nziramasanga, C. T. (1999). Report of the Presidential Inquiry into Education and Training. Harare: Government Printers.

Stewart, J., Sithole, E., Ncube, W., Moyo, T. Gwaunza, E., Nzira, T., Dengu-Zvobgo, K., Mashiangaidze, D., Donzwa, B. \& Kazembe, N. (2000). In the shadow of the Law-Women and Justice Delivery in Zimbabwe, Women and Law in Southern Africa Research Trust (WLSA). Harare: Bardwell Printers.

Wirth, L.(2001). 'Breaking Through the Glass Ceiling)- Women in Management. Geneva: International Labour Office.

Zimbabwe Education Act (as amended as at $1^{\text {st }}$ October, 2004). Retrieved from www.parlzim.gov.zw/actslist/education-act-25-04 